\title{
STRUCTURAL ROBUSTNESS OF LIFE SATISFACTION SCALE OF PRE-SERVICE TEACHERS IN NIGERIA
}

\author{
Joseph Taiwo Akinboboye ${ }^{1}$, Musa Adekunle Ayanwale ${ }^{2}$ and Joseph Adekunle Akande ${ }^{3}$ \\ Science Education, Faculty of Education, Federal University of Lafia, Nasarawa State, Nigeria ${ }^{1}$ \\ Education Foundations, Kampala International University, Kampala, Uganda ${ }^{2}$ \\ Educational Psychology, FCT College of Education, Zuba, Abuja, Nigeria ${ }^{3}$
}

\begin{abstract}
This paper investigated the structural robustness of the Life Satisfaction Scale (LSS) among Nigerian Pre-service Teachers. The study anchors on scale development research type of non-experimental design. Participants were selected randomly, totaling 509. The adopted instrument titled satisfaction with life scale with content validity index of 0.84 and ordinal alpha reliability of $(\alpha=0.75)$ aided in gathering data for the study. Obtained data were analysed using Exploratory Factor Analysis (EFA), Confirmatory Factor Analysis (CFA), and concurrent validity (that is equating with Rosenberg Self Esteem scale), respectively. The results showed that a single trait was evident in the scale, with Eigenvalues of 2.41,0.97, 0.64, 0.53, and 0.44. Also, the CFA indicated a good fit to the data with compliance indices. A significant positive correlation of the LSS with the Rosenberg self-esteem scale $(r=0.83$, $P<0.05)$ indicated acceptable concurrent validity. Similarly, LSS maintains its strict invariance regarding gender. The authors concluded that there was psychometric confirmation for a unitary structure of LSS in Nigeria, and since the two scales produced high correlations, the validity of LSS is referred to as concurrent. Therefore, it was recommended that LSS be used to complement scales that emphasise emotional well-being since it accesses an individual's conscious evaluative judgment of his or her life using personal criteria.
\end{abstract}

KEYWORDS: Confirmatory Factor Analysis; Exploratory Factor Analysis; Life Satisfaction Scale; Ordinal Alpha; Rosenberg Self-Esteem Scale

Corresponding Author: Joseph Taiwo Akinboboye Email:josephakin2014@gmail.com 


\section{INTRODUCTION}

In life, individual values vary from one person to another. What is important to one may not be important to another because what satisfies individuals vary widely. Life Satisfaction Scale (LSS) was originally developed by Diener, Emmons, Larsen, and Griffin (1985) to measure individual satisfaction with life in total. Many researchers have overwhelmingly used it. The scale does not measure satisfaction with life domains such as health or finances but allows respondents to integrate and weigh this domain in any way they choose (Pavot \& Diener, 2008).

Various methods of a quantitative assessment of structural robustness have been proposed and widely discussed in recent years (Wolinski, 2013). Robustness can have different meanings in different fields of science and technology, including assessment of the system, probabilistic investigation, mathematical modelling, software development, products, and procedures. Generally, robustness is the property of a considered system that enables it to survive unforeseen or extraordinary exposures or circumstances that would otherwise cause them to fail or to lose function (Wolinski, 2013). The structural robustness of LSS in this context means that the scale can handle variability and remain effective. LSS retains its adequate reliability, factor structure, acceptable concurrent validity gender invariant with previous studies.

A lot of studies on gender invariances reported as; strict invariance in Norwegian youth and adults (Clench-Aas, Nes, Dalgard \& Aarø, 2011), Taiwanese undergraduates ( $\mathrm{Wu}$ and Yao, 2006), British (Shevlin, Brunsden \& Miles, 1998), Malaysian adults (Swami \& Chamorro-Premuzic, 2009) and Chinese adults (Bai, Wu, Zheng, \& Ren, 2011 cited in Esnaola, Benito, Antonio-Agirre, Freeman \& Sarasa, 2017). Other researches have shown metric invariance in Norwegian adolescents (Moksnes, Løhre, Byrn, \& Haugan, 2014) and scalar invariance in Swedish undergraduates (Hultell \& Gustavson, 2008).
Many researchers have used variables like education, employment, economic status to examine the impact of life satisfaction (Diener \& Chan, 2011; Oishi, Diener, Lucas \& Suh, 2009; Pavot \& Diener, 2008). According to Pavot and Diener (1993) cited in LopezOrtega, Torress-Castro \& Rosas-Carrasco (2016), life satisfaction refers to a judgmental process in which individuals measure their quality of life based on their own set of unique standards. Psychometric attributes of LSS has been investigated among various populations (Morrison, Tay \& Diener, 2011; Aishvarya, Maniam, Karuthan, Sidi, Jaafar \& Oei, 2014) and in divergent cultures and nations of the world Spanish (Vázquez, Duque \& Hervás, 2013), Mexican (Lopez-Ortega, Torress-Castro \& RosasCarrasco, 2016). Portuguese (Sancho, Galiana, Gutierrez, Francisco, \& Tomas 2014), French (Blais, Vallerand, Pelletier, Briere (1989), Turkish (Durak, Senol-Durak, Gencoz (2010), Chinese (Bai, Wu, Zheng, \& Ren, 2011) and Dutch (Arrindell, Meeuwesen, \& Huyse (1991).

Subsequently, the LSS has been found to represent a single construct (Lopez-Ortega et al., 2016; Atienza, Pons, Balaguer \& GarcíaRMerita, 2000; Saman, Azadeh, Reza, \& Zahra, 2016). Many investigations have shown that its structural integrity is unquestionable. Different types of validities are the Criterion-related validity (Schimmack, Oishi, Furr, \& Funder, 2004; Saman et al., 2016), Factorial validity (Diener et al., 1985; Saman et al., 2016), Reliability, and its homogeneity (Saman et al., 2016; LopezOrtega et al., 2016). Some of these researches have reported item number five on the scale to have recorded poor factor loading compared to the rest of the items (e.g., Pavot \& Diener, 1993; Vásquez et al., 2013). Pavot and Diener (1993) said that the item attends to the past adaptation against the present adaptation compared to the remaining four items. In their study, they observed that LSS had higher correlation with the present $(r=.92)$ compared to past $(\mathrm{r}=.72)$ and future $(\mathrm{r}=.59)$ time plan. Previous studies have also examined the convergent, concurrent, and divergent validity of the scale and demonstrated suitable correlations with other measures of life satisfaction (Galanakis, Lakioti, 
Pezirkianidis, Karakasidou \& Stalikas, 2017; Pavot \& Diener, 1993; Pavot, Diener, Colvin \& Sandvik, 1991).

Lopez-Ortega et al. (2016) investigated psychometric properties of the satisfaction with life scale with samples from the 2012 Mexican and Healthy Aging Study. The participants' ages are from 50 years and above. The study revealed adequate reliability and construct validity of the Satisfaction With Life Scale (SWLS) in the Mexican context. The study centred on adults of 50 years and above in Mexico and not pre-service teachers in Nigeria.

Maria, Sousa ${ }^{\mathrm{a}}$, Santos ${ }^{\mathrm{a}}$, \& Sobreira (2015) evaluated construct validity and psychometric properties of the Satisfaction With Life Scale (SWLS) in the Brazilian context. The study sampled 101 individuals from the general population with ages from 18 to 94 years. Results indicated a single factor structure and satisfactory internal consistency. The study conducted in Brazil contained all participants from Brazil. To the best of the researchers' knowledge, this has not been examined within the context of Nigeria.

Akinboboye, Akande, Jimoh \& Adewuni (2016) examined the psychometric properties of the Rosenberg Self Esteem Scale (RSES) among preservice teachers in Nigeria to measure the RSES internal consistency, and three reliability measures were used, namely: Cronbach Alpha (0.473), Guttman coefficient (0.506) and Speraman Brown (0.468). Factor analysis revealed one factor with eigenvalue greater than two accounted for $16.684 \%$ of the variance in test scores. The result revealed that RSES has a unitary factor structure. The study was carried out among Nigerian pre-service teachers using the RSES instrument, not the LSS instrument.

Also, Cronbach alpha, which has been criticised in the literature (Cronbach, 2004;1951) for its spurious estimation, was used in the previous studies to establish reliability. In this study, ordinal alpha for estimating reliability with the ordinal nature of the dataset was used (Gadermann, Guhn, \& Zumbo, 2012).
Lastly, Musaitif (2018) investigated the psychometric properties of the Satisfaction With Life Scale among Arab Americans and found the instrument's strong validity. This study was conducted in America among Arabian, not preservice teachers in Nigeria.

Although some of the authors in the empirical literature reviewed for this study focused on the structural robustness of LSS, no such study has been done among Nigerian pre-service teachers. Therefore, the purpose of this study was to assess the structural robustness of the Life Satisfaction Scale (LSS) among Nigerian pre-service teachers. Currently, the structural robustness of LSS and its applications among the Nigerian youth are undisclosed. Specific objectives of the study were to substantiate the internal consistency, to determine the factorial structure and concurrent validity and also to know if gender significantly influences the responses of LSS items among Nigerian pre-service teachers.

Research questions for this study were four-fold. These include; Do the items in LSS have a measure of internal consistency? What is the dimensionality of LSS among Nigerian pre-service teachers? Do the items in the two scales (LSS and RSES) establish concurrent validity among Nigerian pre-service teachers? Does gender have a significant influence on the responses of LSS items?

\section{METHODOLOGY}

The study is anchored on a scale development research type of non-experimental design. The population for the study consisted of all pre-service teachers (student teachers) in Federal Capital Territory (FCT) College of Education, Zuba, Abuja. The total population of the students was 6,345. The college has 29 departments (Psychology, Curriculum, Educational Foundation, General Studies in English, Early Childhood Care Education, Primary Education Studies, Christian Religious Studies, Islamic Studies, Economics, Geography, Social Studies, History, English Language, French, Arabic, Hausa, Igbo, Yoruba, Biology, Computer, Mathematics, Physics, 
Chemistry, Integrated Science, Physical and Health Education, Agricultural Science, Home-Economics, Business Education and Fine Arts) in which 21 students from each of the 25 departments were randomly selected through lottery method of simple random sampling technique to make a total of 525 students, but only 509 of them returned the questionnaires and participated in the study. The remaining four departments (Psychology, Curriculum, Educational Foundation, and General Studies in English) were excluded because they took courses from them. The researchers used the sample size table provided by Krejcie \& Morgan (1970) to guide sample size selection. 224 males represented (44\%) with a mean age of 23.4 years and 285 females represented $54 \%$ with a mean age of 22.3 years. The instruments used for data collection were Life Satisfaction Scale (Diener et al., 1985) and Rosenberg Self-esteem Scale (RSES; Rosenberg, 1965).

Life Satisfaction Scale: The Life Satisfaction Scale (LSS) is an instrument that measures the cognitive aspect of subjective wellbeing. It comprised of five items measured on 7-point Likert response format. The five statement items are: in most ways, my life is close to my ideal, the conditions of my life are excellent, I am satisfied with life, I have gotten the important things I want in life, and If I could live my life over, I would change almost nothing.

\section{Rosenberg developed Rosenberg Self Esteem} Scale (RSES), 1965 cited in Akinboboye et al. (2016) to appraise self-esteem in adolescents and children. The scale has 10 items with a 4-point Likert type (i.e., Strongly Agree, Agree, Disagree, Strongly Disagree). Five out of the ten items are negatively worded, and the remaining five are positively worded. The positively worded are: I feel that I am a person of worth, at least on an equal plane with others, I can do things as well as most other people, I take a positive attitude toward myself, I feel that I have many good qualities, On the whole, I am satisfied with myself. The negatively worded are: I feel that I do not have much to be proud of; all in all, I am inclined to feel that I am a failure, I wish I could have more respect for myself, and I certainly feel useless at times. To examine the structural robustness of LSS, first, the reliability of the scale was carried out through Ordinal alpha reliability. Second, Exploratory Factor Analysis was performed to determine the construct validity of the instrument. Preliminary data verification through Barlett's Test of Sphericity was conducted to ascertain the appropriateness of factor analysis. This helps to know if the items were correlated in the population.

Furthermore, Confirmatory Factor Analysis (CFA) was conducted to establish the goodness of fit of the identified single-factor model. Concurrent validity between LSS and RSES was established through Pearson Product Moment Correlation (PPMC). Lastly, a t-test analysis was conducted to determine the influence of gender on the responses of LSS items. All analyses were carried out using Lisrel Statistical Software version 8.80 and Statistical Package for Social Sciences (SPSS) version 20.

\section{RESULTS}

\section{Research Question 1: Do the items in LSS}

\section{have a measure of internal consistency?}

\section{Reliability of the Instrument}

Answering this research question, Ordinal alpha reliability was conducted using R-programming language, and the coefficient for assessing internal consistency of the LSS was 0.75 (see Table 1 below). Ordinal Alpha Reliability Implemented in $\mathrm{R}$ Programming Language.

$\begin{array}{cccccc}\text { raw_alpha } & \text { std.alpha } & \text { G6 }(\mathrm{smc}) & \text { average_r } & \text { S/N } & \text { median_r } \\ 0.75 & 0.75 & 0.74 & 0.38 & 3.1 & 0.38\end{array}$

Table 1: Reliability if an item is dropped

\begin{tabular}{|c|c|c|c|c|c|c|c|}
\hline Item & $\begin{array}{l}\text { raw_- } \\
\text { alpha }\end{array}$ & $\begin{array}{l}\text { std. } \\
\text { alpha }\end{array}$ & G6(smc) & average_r & $\mathrm{S} / \mathrm{N}$ & var.r & med.r \\
\hline 1 & 0.71 & 0.71 & 0.68 & 0.38 & 2.5 & 0.023 & 0.37 \\
\hline 2 & 0.68 & 0.68 & 0.64 & 0.35 & 2.1 & 0.0179 & 0.34 \\
\hline 3 & 0.66 & 0.66 & 0.62 & 0.33 & 1.9 & 0.0204 & 0.34 \\
\hline 4 & 0.7 & 0.7 & 0.67 & 0.37 & 2.3 & 0.0374 & 0.38 \\
\hline 5 & 0.79 & 0.79 & 0.74 & 0.48 & 3.7 & 0.0075 & 0.49 \\
\hline
\end{tabular}




\begin{tabular}{lrrr}
\hline \multicolumn{4}{c}{ Item statistics } \\
\hline Item & \multicolumn{1}{c}{ R } & \multicolumn{1}{c}{ r.cor } & \multicolumn{1}{c}{ r.drop } \\
\hline 1 & 0.71 & 0.61 & 0.52 \\
2 & 0.77 & 0.71 & 0.6 \\
3 & 0.8 & 0.76 & 0.66 \\
4 & 0.73 & 0.62 & 0.55 \\
5 & 0.54 & 0.35 & 0.3 \\
\hline
\end{tabular}

From the findings of this study, the scale has an adequate level of reliability with an Ordinal alpha coefficient of 0.75 .

\section{Research Question 2: What is the dimensionality of} LSS?

\section{Exploratory Factor Analysis (EFA)}

The preliminary analysis of Barlett's test of sphericity produced 525.068 at $\mathrm{p}<0.05$ level of significance. This shows a high correlation among the items. Also, the Kaiser Meyer-Olkin index produced a 0.76 value which shows the appropriateness of the data for factor analysis. The EFA ensued in a single factor, explaining $48.28 \%$ of total variance with an eigenvalue of 2.414 (see Table 2)

Table 2: Eigen value and total variance explained of LSS

\begin{tabular}{|c|c|c|c|c|c|c|}
\hline \multicolumn{7}{|c|}{ Total Variance Explained } \\
\hline & \multicolumn{3}{|c|}{ InitialE gensalues } & \multicolumn{3}{|c|}{$\begin{array}{l}\text { Extraction sunr of squared } \\
\text { loading }\end{array}$} \\
\hline Conponent & Total & $\begin{array}{l}\% \text { of } \\
\text { varince }\end{array}$ & $\underset{\%}{\operatorname{Cunmm}}$ & Total & $\begin{array}{l}\% \text { of } \\
\text { varinnce }\end{array}$ & $\underset{\%}{\operatorname{Cummm}}$ \\
\hline 1 & 2.414 & 48.277 & 48.277 & 2.414 & 48.277 & 48277 \\
\hline 2 & .968 & 19.368 & 67.646 & & & \\
\hline 3 & .642 & 12.844 & 80.490 & & & \\
\hline 4 &.$\$ 34$ & 10.684 & 91.174 & & & \\
\hline 5 & .441 & 8.826 & 100.000 & & & \\
\hline
\end{tabular}

Extraction Method: Principal Component Analysis

A Scree plot was employed to represent the eigenvalues and the number of factors graphically. It is evident from the Scree plot that the single-factor model was appropriate to represent the data (see Figure 1).

Table 3: Factor Loadings of LSS

\begin{tabular}{|c|l|l|}
\hline s/n & \multicolumn{1}{|c|}{ Item } & Factor \\
\hline 1 & $\begin{array}{l}\text { In most ways my life is close to my } \\
\text { ideal }\end{array}$ & .60 \\
\hline 2 & $\begin{array}{l}\text { The conditions of my life are } \\
\text { excellent }\end{array}$ & .73 \\
\hline 3 & I am satisfied with my life & .74 \\
\hline 4 & $\begin{array}{l}\text { So far, I have gotten the important } \\
\text { things I want in life }\end{array}$ & .55 \\
\hline 5 & $\begin{array}{l}\text { If I could live my life over, I would } \\
\text { change almost nothing }\end{array}$ & .30 \\
\hline
\end{tabular}

It would be preferable if the first factor accounted for more variance. However, Wiberg (2004) stated that it is not uncommon to have this type of situation. As long as there is one factor with a distinctly larger eigenvalue, it is possible to assume the unitary dimension in the test. From Table 3, the items factor

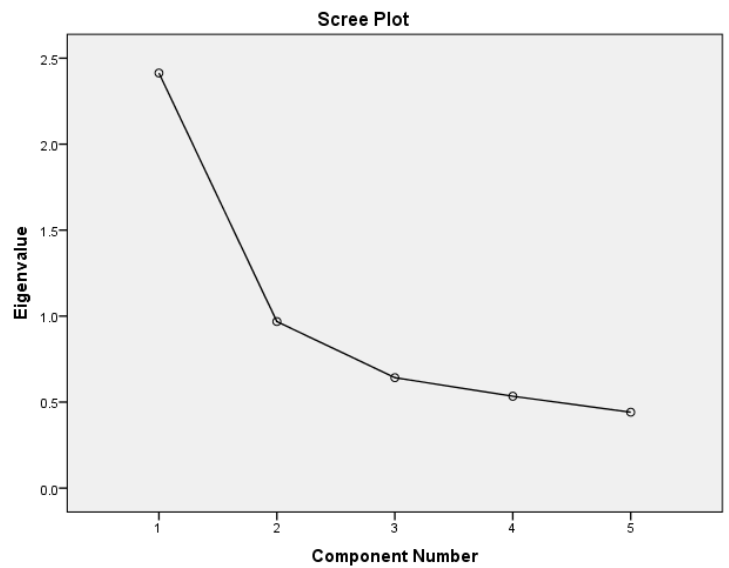

loading varies from .30 for item 5 to .74 for item 3 .

Figure 1: The scree plot (Cattell) of LSS

\section{Confirmatory Factor Analysis}

Confirmatory Factor Analysis (CFA) was conducted to establish the goodness of fit of the identified single-factor model. Table 4 below shows the values of the four most widely used goodness of fit indicators revealing a single-factor model that fits the scale. They are Normed Fit Index (NFI), Comparative Fit Index (CFI), Root Mean Square Error of Approximation (RMSEA), and Goodness of Fit Index (GFI) (Bentler \& Bonett 1980; Tanaka \& Huba, 1984; Steiger \& Lind, 1980).

RMSEA is a measure of how a model fits a set of data. A zero value shows that the model fits the data absolutely; values less than .05 shows that the model indicates a good fit with the data; a value between .08 and .10 shows a mediocre fit, and values above .10 show a poor fit (Browne \& Cudeck, 1993; MacCallum et al., 1996). CFI and NFI produce value ranges between 0 and 1 where high value shows a good fit. CFI value of 0.97 shows that the fit is better compared to the model (Schermelleh-Engel \& Moosbrugger, 2003; Chen, 2007; Hu \& Bentler, 1999). 
Table 4: Goodness of fit indices that shows how a single factor model fit LSS

\begin{tabular}{|c|c|c|c|c|}
\hline Scale & RMSEA & GFI & NFI & CFI \\
\hline LSS & 0.104 & 0.98 & 0.92 & 0.96 \\
\hline
\end{tabular}

The standard factor loadings for the single-factor model are shown in figure 2. All factor loadings were significant and in the expected direction

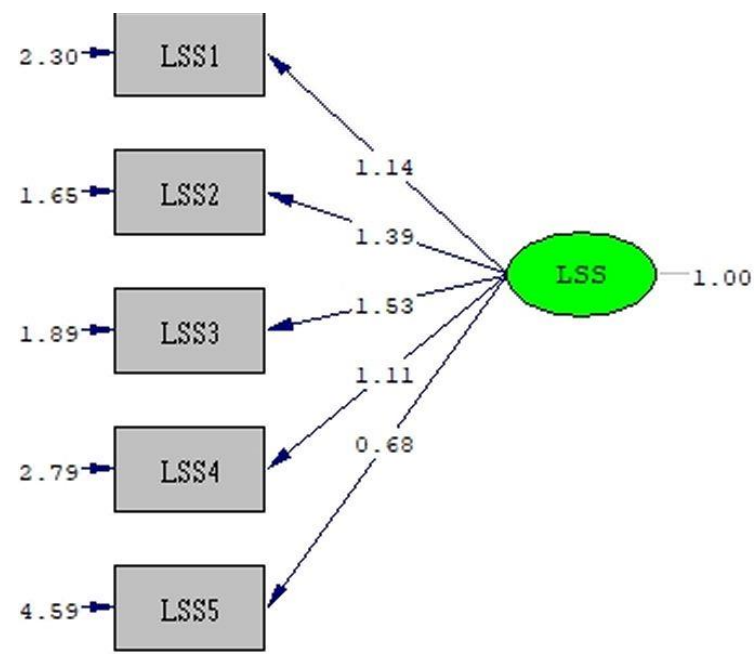

Chi-Square $=32.45, \mathrm{df}=5, \mathrm{P}$-value $=0.00000$, RMSEA $=0.104$

Figure 2: Standard factor loadings for the singlefactor model.

The model fit indices of LSS are shown in Figure 2. The five-item model of LSS demonstrated a good fit for the data. The LSS factor loadings were statistically significant and ranged from 0.68 to 1.53 .

Research Question 3: Do items in the two scales (LSS and RSES) establish concurrent validity among Nigerian pre-service teachers?

In order to analyse the concurrent validity of the LSS, the Pearson product-moment correlation coefficient was calculated between LSS and RSES. The LSS was significantly positively correlated with RSES $(\mathrm{R}=$ $0.83, \mathrm{P}<0.05)$, indicating acceptable concurrent validity.

Research Question 4: Does gender have a significant influence on the responses of LSS items? The responses of the male and female pre-service teachers were subjected to t-test analysis, and the results are shown in Table 5.

Table 5: t-test analysis of gender invariance in LSS items

\begin{tabular}{|c|c|c|c|c|c|}
\hline Gender & N & Mean & df & t & sig \\
\hline Male & 224 & 23.03 & 507 & -.808 & .419 \\
\cline { 1 - 3 } Female & 285 & 23.53 & & & \\
\hline
\end{tabular}

Table 5 showed no significant difference between male and female pre-service teachers in their responses to LSS items since $\mathrm{t}=-.808$ and $\mathrm{p}>.05$. This implies that LSS is gender invariant.

\section{DISCUSSION}

The LSS was aimed to measure the cognitivejudgmental dimension of subjective well-being. The main purpose of this study was to assess the structural robustness of the LSS among the Nigerian Preservice teachers. The sample of 509 pre-service teachers was considered to assess the reliability, construct, and concurrent validity of the LSS. From the findings of this study, the scale has an adequate level of reliability with an Ordinal alpha coefficient of 0.75 . This finding corroborated the findings of previous researchers like Galanakis et al., 2017; Saman et al., 2016; Lopez-Ortega et al., 2016. Their studies revealed adequate reliability and construct validity.

All LSS items presented higher factor loadings except Item 5 that displayed the weakest factor loading of .30. Following the explanation to justify this, Pavot and Diener (1993) said that the item attends to the past adaptation against the present adaptation compared to the remaining four items. In their study, they observed that LSS had a higher correlation with the present $(\mathrm{r}=.92)$ compared to past $(\mathrm{r}=.72)$ and future $(\mathrm{r}=.59)$ time plan. Moreover, the results from the study confirm the single-factor model of the scale buttressing the findings of the previous researchers (Diener et al., 1985; Atienza et al., 2000; Maria et al., 2014; Lopez-Ortega et al., 2016; Musaitif, 2018). In addition, the EFA also revealed a unique factor that explained $48.28 \%$ of the total variance. The outcomes of both CFA and EFA show that LSS has a unitary dimension among 
Nigerian pre-service teachers.

The study outcomes revealed supplementary evidence for the construct of LSS, which positively correlated with RSES that corroborated previous findings (Galanakis et al. 2017; Pavot \& Diener, 1993; Pavot et al. 1991).

Lastly, the study results showed that LSS is gender invariant since no significant difference exists between male and female pre-service teachers in their responses to LSS items. This finding supported the previous findings (Wu \& Yao, 2006), British (Shevlin, Brunsden \& Miles, 1998), Malaysian adults (Swami \& Chamorro-Premuzic, 2009), and Chinese adults (Bai, Wu, Zheng, \& Ren, 2011).

\section{CONCLUSION}

In conclusion, the study examined the structural robustness of LSS among 509 Nigerian pre-service teachers and showed adequate reliability, factor structure, and acceptable concurrent validity, in agreement with previous studies. The LSS has adequate structural robustness for assessing life satisfaction in Nigerian pre-service teachers and maintained gender invariance.

\section{RECOMMENDATIONS}

Researchers can use LSS to examine life satisfaction among adult youths in Nigeria and countries of comparable economic and cultural backgrounds. Furthermore, LSS can be used as a complement for scales that focus on emotional wellbeing since it accesses an individual's conscious evaluative judgment of their life using personal criteria. Despite the findings, this study possesses a few limitations. First, the study is limited to the population of students in a College of Education. Second, the study is limited to pre-service teachers (young adults) in Nigeria. Future studies can include populations from different higher institutions and adults above the age bracket used in this study.

\section{REFERENCES}

Aishvarya, S.; Maniam, T.; Karuthan, C.; Sidi, H., Jaafar, N. R. N.; Oei, T. P. S. (2014). Psychometric properties and validation of the Satisfaction with Life Scale in psychiatric and medical outpatients in Malaysia. Compr. Psychiatry 55 S101-S106.

Akinboboye, J. T;, Akande, J. A.; Jimoh, M. I., \& Adewuni, D. A. (2016). Psychometric Properties of the Rosenberg Self-Esteem Scale in Nigerian Preservice Teachers in T. L. Adepoju (Ed.). Critical Areas of Educational Development in Africa. LINCOM GmbH Press. pp 339-349.

Arrindell, W. A.; Meeuwesen, L.; Huyse, F. J. (1991). The satisfaction with life scale: psychometric properties in a non-psychiatric medical outpatients sample. Pers Individ Dif. 12, pp. 117-123.

Atienza, F. L.; Pons, D., Balaguer, L., \& GarciaMerita, M. L. (2000). Propiedades psicometricas de la Escala de Satisfaccion'con la Vida en adolescentes. Psicothema, 12(2), pp. 314-319.

Bai, X.; Wu, C. Zheng; R. \& Ren, X. (2011). The psychometric evaluation of the satisfaction with life scale using a nationally representative sample of China. Journal of Happiness Studies, 12(2), pp. 183197. doi: 10.1007/s10902-010-9186-x.

Bentler, P. M. \& Bonett, D. G. (1980). Significance tests and goodness of fit in the analysis of covariance structure, Psychological Bulletin, 88, pp. 588-606.

Blais, M. R., Vallerand, R. J., Pelletier, L. G., \& Brière, N. M. (1989). The satisfaction scale: Canadian-French validation of the satisfaction with life scale. Can J. Behav Sci,, 21(2), pp. 10-23.

Browne, M. W., \& Cudeck, R. (1993). Alternative ways to assessing model fit. In K. A. Bollen \& J. S. Long (Eds.). Testing structural equation models (136-162). Newbury. CA: Sage.

Chen, F. F., (2007). Sensitivity of goodness of fit indexes to lack of measurement invariance. 
Structural Equation Modelling: AMultidisciplinary Journal, 14(3). pp. 464-504. Doi: 10.1080/10705510701301834.

Clench-Aas, J.; Nes, R. B., Dalgard, O. D., \& Aarø, L. E. (2011). Dimensionality and measurement invariance in the Satisfaction With Life Scale in Norway. Quality of Life Research, 20, pp. 13071317. https:// doi.org/10.1007/s11136-011-9859-x

Cronbach, L. J. (1951). Coefficient alpha and the internal structure of tests. Psychometrika, 16, pp. 297- 334.

Cronbach, L. J. \& Shavelson, R. J.(2004). My Current Thoughts on Coefficient Alpha and Successor Procedures. Educational and Psychological Measurement, 64, pp. 391-418. Doi:10.1177/0013164404266386.

Diener, E., \& Chan, M. Y. (2011). Happy people live longer: Subjective wellbeing contributes to health and longevity. Appl Psychol. 3(1), pp. 1-43.

Diener, E., Emmons, R. A., Larsen, R. J., \& Griffin, S. (1985). The Satisfaction With Life Scale. Journal of Personality Assessment, 49, pp. 71-75.

Durak, M.; Senol-Durak; E., \& Gencoz, T. (2010). Psychometric properties of the satisfaction with life scale among Turkish university students, correctional officers, and elderly adults. Social Indicators Research, 99(3), pp. 413-429. doi: 10.1007/s11205010-9589-4

Esnaola, I., Benito; M., Antonio-Agirre, I.; Freeman, J. \& Sarasa, M. (2017). Measurement invariance of the Satisfaction With Life Scale (SWLS) by country, gender, and age. Psicothema, 29, (4), pp. 596-601 doi: 10.7334/psicothema2016.394.

Gadermann, A. M.; Guhn, M., \& Zumbo, B. D. (2012). Estimating ordinal reliability for Likerttype and ordinal item response data: A conceptual, empirical, and practical guide Practical Assessment, Research, and Evaluation: 17, Article 3.doi: 10.7275/n560-j767.
Galanakis, M., Lakioti, A., Pezirkianidis, C., Karakasidou, E., \& Stalikas, A. (2017). Reliability and Validity of the satisfaction with life scale in a Greek sample. International Journal of Humanities and Social Studies, 5(2), pp. 120-127.

Hu, L. T., \& Bentler, P. M. (1999). Cutoff criteria for fit indexes incovariance structure analysis: Conventional criteria versus new alternatives. Structural Equation Modeling: A Multidisciplinary Journal, 6(1), pp. 1-55. doi: 10.1080/10705519909540118.

Hultell, D., \& Gustavson, J. P. (2008). A psychometric evaluation of the Satisfaction With Life Scale in a Swedish nationwide sample of university students. Personality and Individual Differences, 44, pp. 1070- 1079.

doi:10.1016/j.paid.2007.10.030.

Krejcie, R.V., \& Morgan, D.W. (1970). Determining Sample Size for Research Activities. Educational and Psychological Measurement.

López-Ortega, M., Torres-Castro, S., \& RosasCarrasco, O. (2016). Psychometric properties of the Satisfaction with Life Scale (SWLS): secondary analysis of the Mexican Health and Aging Study. Health and Quality of Life Outcomes 14, 170. doi:10.1186/s12955-016-0573-9.

MacCallum, R. C.; Browne, M. W.; \& Sugawara, H. M. (1996). Power analysis and determination of sample size for covariance structure modeling. Psychological Methods, 1, pp. 130-149.

Maria, E., Sousa;, P. De., Santos; W. S., \& Sobreira, G. (2015). Satisfaction with Life Scale : Evidence of Validity and Reliability in the Brazilian Context. Social Inquiry into Well-Being 1(2), 41-50. doi:10.13165/SIIW-15-1-2-06

Moksnes, U.K.; Løhre, A., Byrn; D.G., \& Haugan, G. (2014). Satisfaction With Life Scale in adolescents: Evaluation of factor structure and gender invariance in a Norwegian sample. Social Indicators Research, 118, 657-671. doi:10.1007/s11205-013-0451-3. 
Morrison, M.; Tay, L.; Diener, E. (2011). Subjective Well-Being and National Satisfaction Findings from a Worldwide Survey. Psychol.Sci., 22, pp. 166-171.

Musaitif, A. (2018). Psychometric Properties of the Satisfaction with Life Scale Among Arab Americans. Dissertations (1934-).p. 790.

Oishi, S.; Diener E.; Lucas, R. E.; Suh, E. M. (2009). Cross-cultural variations in predictors of life satisfaction: Perspectives from needs and values, culture and well-being: The collected works of Ed Diener. New York, NY: Springer Science + Business Media; pp. 109-27.

Pavot, W, \& Diener, E. (2008): The satisfaction with life scale and the emerging construct of life satisfaction. The Journal of Positive Psychology, 3(2), pp. 137-152.

Pavot, W., \& Diener, E. (1993): Review of the satisfaction with life scale. Psychological Assessment, 5, pp. 164-172.

Pavot, W., Diener, E.; Colvin, C. R., \& Sandvik, E. (1991).Further validation of the Satisfaction With Life Scale: Evidence for the cross-method convergence of well-being measures. Journal of Personality Assessment, 57, pp. 149-161.

Rosenberg, M. (1965). Society and the adolescent self-image. NJ: Princeton University Press.

Saman, M.; Azadeh, G.; Reza, O. S.; \& Zahra, E. (2016). Psychometric properties of the Satisfaction With Life Scale in Iranian infertile women. International Journal of Reproductive BioMedicine, 14 (1), pp. 57-62.

Sancho, P., Galiana; L., Gutierrez, M.; Francisco, E. H., \& Tomas, J. M. (2014). Validating the Portuguese version of the satisfaction with life scale in an elderly sample. Social Indicators Research, 115(1), pp. 457 466. doi: 10.1007/s11205-012-9994-y.
Schermelleh-Engel, K., \& Moosbrugger, H. (2003). Evaluating the fit of structural equation models: Test of significance and descriptive goodness-of-fit measures. Method of Psychological Research Online, 8(2), pp. 23-74.

Schimmack, U.; Oishi, S.; Furr, R. M., \& Funder, D. C. (2004). Personality and life satisfaction: A facet level analysis. Personality and Social Psychology Bulletin, 30, pp. 1062-1075.

Shevlin, M.; Brunsden, V., \& Miles, J.N.V. (1998). Satisfaction With Life Scale: Analysis of factorial invariance, mean structures, and reliability. Personality and Individual Differences, 25, pp. 911916. Doi:10.1016/s0191-8869(98)00088-9.

Steiger, J., \& Lind, J. (1980). Statistically-based tests for the number of common factors. Paper presented at the Annual Meeting of the Psychometric Society, Iowa City, IA.

Swami, V., \& Chamorro-Premuzic, T. (2009). Psychometric evaluation of the Malay Satisfaction With Life Scale. Social Indicators Research, 92, pp.25-33. doi:10.1007/s11205-008-9295-7.

Tanaka, J. S., \& Huba, G. J. (1985). A fit index for the covariance structure models under arbitrary GLS estimation. British Journal of Mathematical and Statistical Psychology. 38, pp. 197-201.

Vázquez, C.; Duque, A., \& Hervás, G. (2013). Satisfaction with life scale in a representative sample of Spanish adults: validation and normative data. Span. J. Psychol, 16, pp.1-15.

Wiberg, M. (2004). Classical Test Theory versus Item Response Theory. An Evaluation of the Theory of Test in the Sweeden Driving-License Test. Retrieved from www.umcl.se 12/02/15.

Wu, C., \& Yao, G. (2006). Analysis of factorial invariance across gender in the Taiwan version of the Satisfaction With Life Scale. Personality and Individual Differences, 40, pp. 1259-1268. doi:10.1016/j. paid.2005.11.012. 
Wolinski, S. (2013). Defining of the structural robustness. Bulletin of the polish academy of sciences technical sciences, 61(1), 137-144. PS doi: 10.2478/bpasts-pp. 2013-0012. 